\title{
VALUASI EKONOMI EKOSISTEM TERUMBU KARANG PULAU WARBAL DI KAWASAN KONSERVASI KEI KECIL KABUPATEN MALUKU TENGGARA
}

\author{
(Economic Valuation of Warbal Island Coral Reef Ecosystem in \\ Kei Kecil Conservation Area, Southeast Maluku Regency)
}

\author{
Mentari A. Mahakena ${ }^{1}$, Stevanus M. Siahainenia ${ }^{2}$ dan Dicky Sahetapy ${ }^{3}$ \\ ${ }^{I}$ Mahasiswa Program Studi Magister Manajemen Sumberdaya Kelautan dan Pulau-Pulau Kecil Program Pascasarjana \\ Universitas Pattimura \\ ${ }^{2}$ Jurusan Agrobisnis Perikanan Fakultas Perikanan dan Ilmu Kelautan Universitas Pattimura \\ ${ }^{3}$ Jurusan Manajemen Sumberdaya Perairan Fakultas Perikanan dan Ilmu Kelautan Universitas Pattimura \\ ammahakena@gmail.com,steviesiahainenia@gmail.com,dicky_sahetapy@yahoo.com \\ Corresponding author*
}

\begin{abstract}
ABSTRAK: Valuasi ekonomi berperan penting sebagai instrument yang komperhensif untuk memberi penilaian harga (price tag) terhadap keberadaan barang dan jasa suatu ekosistem. Penelitian ini bertujuan untuk menganalisis nilai pemanfaatan, nilai non pemanfaatan dan nilai ekonomi total sumberdaya terumbu karang serta merumuskan strategi pengelolaan ekosistem terumbu kawasan Pulau Warbal dan perairan sekitarnya. Penelitian tentang valuasi ekonomi ekosistem terumbu karang Pulau Warbal dan perairan sekitarnya dilakukan pada Juli-Nopember 2019. Pengumpulan data primer dilakukan melalui pengamatan lapangan dan wawancara, sedangkan data sekunder diperoleh melalui referensi dari Pemerintah Desa, Dinas Perikanan Maluku Tenggara, WWF Indonesia dan publikasi ilmiah. Data dianalisis menggunakan metode analisis nilai ekonomi total dari use value dan non use value. Berdasarkan hasil penelitian diperoleh nilai ekonomi total dari pemanfaatan dan non pemanfaatan sumberdaya terumbu karang kawasan Pulau Warbal dan perairan sekitarnya mencapai Rp. 7.275.603.819/tahun. Nilai pemanfaatan sumberdaya terumbu karang Pulau Warbal dan perairan di sekitarnya sebesar Rp. 7.257.318.819/tahun, sedangkan nilai non pemanfaatan sumberdaya terumbu karang sebesar Rp. 18.250.000/tahun. Terdapat 11 strategi dan 22 arahan pengelolaan yang direkomendasikan untuk pengelolaan sumberdaya terumbu karang Pulau Warbal dan perairan di sekitarnya.
\end{abstract}

Kata kunci: valuasi ekonomi, ekonomi total, nilai pemanfaatan, terumbu karang, Maluku Tenggara

ABSTRACT: Economic valuation plays an important role as a comprehensive instrument to
assess prices (price tags) on the existence of goods and services of an ecosystem. This
research aims to analyze utilization conditions including utilization value, non-utilization
value and total economic value of coral reef resources and formulate a strategy for managing
the reef ecosystem of Warbal Island and surrounding waters. The research on the economic
valuation of warbal island coral reef ecosystem and surrounding waters was conducted in
July-November 2019 . Primary data collection was done through field observations and
interviews, while secondary data was obtained through references from the Village
Government, Southeast Maluku Fisheries Service, WWF Indonesia and scientific
publications. Data was analyzed using methods of analysis of total economic value from use
value and non-use value. Based on the results of the study obtained the total economic value
of the utilization and non-utilization of coral reef resources in Warbal Island and surrounding 
waters reached IDR. 7.275.603.819/year. The value of utilization of coral reef resources of Warbal Island and surrounding waters amounted to IDR. 7.257.318.819/year, while the nonutilization value of coral reef resources amounted to IDR. 18.250.000/year. At least, there are 11 strategies and 22 management directives recommended for the management of Warbal Island coral reef resources and surrounding waters.

Keywords: economic valuation, total economy, utilization value, coral reefs, Southeast Maluku

\section{PENDAHULUAN}

Pulau Warbal merupakan salah satu gugusan pulau kecil yang masuk dalam Kawasan Konservasi Pesisir Pulau Kei Kecil, Pulau-Pulau dan Perairan Sekitarnya di Kabupaten Maluku Tenggara. Penetapan wilayah konservasi ini berdasarkan keputusan Menteri Kelautan dan Perikanan Republik Indonesia Nomor 6/KEPMEN-KP/2016. Adapun Kawasan Konservasi Perairan dan Pulau-Pulau Kecil (KKP3K) dan perairan di sekitarnya berstatus sebagai Taman Pulau Kecil (TPK) dijelaskan dalam Peraturan Menteri Kelautan dan Perikanan Nomor PER.17/MEN/2008 tentang Kawasan Konservasi di Wilayah Pesisir dan Pulau-Pulau Kecil pasal 6 ayat 4b menyebutkan bahwa Taman Pulau Kecil mempunyai luas pulau kecil/gugusan pulau dan perairan di sekitarnya yang cukup untuk menjamin kelestarian potensi dan daya tarik serta pengelolaan pulau kecil yang berkelanjutan; dan ayat 4c menyebutkan kondisi lingkungan di sekitarnya mendukung upaya pengembangan wisata bahari dan rekreasi.

Potensi sumberdaya dan jasa lingkungan yang dimiliki perairan Pulau Warbal menjadikan kawasan ini juga menjadi laboratorium penelitian bagi para akademisi, Lembaga Llmu Pengetahuan Indonesia (LIPI) dan LSM Konservasi seperti WWF Indonesia. Kawasan perairan Pulau Warbal dan sekitarnya memiliki ekosistem pesisir lengkap yaitu ekosistem mangrove, lamun dan terumbu karang. Secara bioekologis, diyakini ekosistem pulau kecil perairan tropis ini sangat penting bagi kehidupan biota laut. Sebagaimana diketahui, ekosistem terumbu karang memiliki beragam biota laut yang hidup berasosiasi didalamnya, seperti ikan, kerang, lobster dan penyu (Supriharyono, 2007; Rumkorem, $d k k$., 2019).

Sebagai bagian dari KKP3K jenis TPK Kei Kecil, Pulau Warbal memiliki peran penting dari sisi ekologis dan ekonomi bagi masyarakat, tetapi dalam pengelolaannya masih ada berbagai kendala yaitu efektivitas pengelolaan. Efektivitas pengelolaan kawasan konservasi TPK Kei kecil telah berada pada peringkat merah dan berdasarkan perkembangannya dalam dua tahun penilaian termasuk golongan lambat (Abrahamsz, $d k k$., 2017). Penetapan perairan Pulau Warbal sebagai kawasan konservasi seyogyanya diikuti dengan upaya pengelolaan yang tepat. Pulau Warbal yang juga merupakan zona pemanfaatan, masih ditemukan aktivitas penangkapan yang destruktif seperti pengeboman yang mengancam ekosistem terumbu karang. Kerusakan terumbu karang akibat aktivitas antropogenik yaitu penambangan batu karang sebagai bahan bangunan berpengaruh terhadap nilai manfaat ekonomi dan ekologi yang didapat dari keberadaan terumbu karang, mengingat terumbu karang sebagai daerah pemijahan, pengasuhan dan mencari makan dari biota laut bernilai ekonomis tinggi (Ramadhan, $d k k$., 2016; Arisandi, dkk., 2018. Berdasarkan penelitian Abrahamsz, dkk. (2017) diperoleh rata-rata tutupan lamun $60,42 \%$, tutupan mangrove $59,33 \%$ dan terumbu karang hanya $39,13 \%$. Hal ini membuktikan bahwa kondisi terumbu karang di perairan Pulau Warbal dan sekitarnya telah mengalami penurunan.

Keberadaan ekosistem terumbu karang dan keberlanjutan pemanfaatan eksosistem tersebut merupakan kunci sukses dalam keberhasilan kawasan konservasi. Oleh karena itu, valuasi ekonomi sumberdaya berperan 
penting sebagai instrument yang komperhensif dalam memberi penilaian harga (price tag) terhadap keberadaan barang dan jasa ekosistem terumbu karang. Valuasi ekonomi mampu menjawab perhitungan manfaat ekonomi berbasis Marine Protected Area yang dilakukan dengan penyesuaian terhadap kondisi data. Tujuan penelitian ini yaitu menganalisis nilai pemanfaatan, nilai non pemanfaatan dan nilai ekonomi total sumberdaya terumbu karang serta merumuskan strategi pengelolaan ekosistem terumbu kawasan Pulau Warbal dan perairan sekitarnya.

\section{METODE PENELITIAN}

Penelitian ini dilakukan bulan Juli hingga Nopember 2019 di kawasan Pulau Warbal dan perairan sekitarnya, yang berada pada KKP3K Kei Kecil, Pulau-Pulau dan Perairan Sekitarnya di Kabupaten Maluku Tenggara (Gambar 1). Pengambilan data menggunakan metode purposive sampling. Sesuai tujuan penelitian maka setiap pengambilan data, wawancara dilakukan berbasis pertimbangan tertentu (Singarimbun\&Effendi 1989). Pertimbangan dalam pemilihan responden diantaranya keberadaan responden sebagai penduduk lokal, wisatawan dan penduduk sekitar Pulau Warbal dengan aktivitas menangkap ikan di sekitar pulau ini. Karakteristik responden sesuai tujuan penelitian diuraikan sebagai berikut: (1). Mengukur perubahan produktivitas ekosistem terumbu karang Pulau Warbal dan perairan sekitarnya dengan melibatkan nelayan perikanan tangkap, (2) Mengukur market price dengan menjadikan wisatawan (domestik dan mancanegara), dan (3) Mengukur kesediaan untuk membayar terhadap perbaikan ekosistem terumbu karang di Pulau Warbal dengan melibatkan seluruh unsur masyarakat yang berada di Pulau Warbal sebagai responden.

Pendekatan yang digunakan dalam menghitung nilai total ekonomi terumbu karang di kawasan Pulau Warbal dan perairan di sekitarnya adalah melalui perhitungan total economy valuation (TEV), dengan formula sebagai berikut:

$$
\text { TEV }=\text { UV }(\text { DUV + IUV + OV })+\text { NUV }(\text { BV })
$$

Keterangan:

$\begin{aligned} \mathrm{TEV}= & \text { Total Economic Value/ Nilai } \\ & \text { ekonomi total } \\ \mathrm{UV}= & \text { Use Value; } \\ \mathrm{DUV}= & \text { Nilai manfaat langsung (direct use } \\ & \text { value) } \\ \mathrm{IUV}= & \text { Nilai manfaat tidak langsung } \\ & (\text { indirect } \text { use value) } \\ \mathrm{OV}= & \text { Nilai Manfaat Pilihan (Option Value) } \\ \mathrm{NUV}= & \text { Non Use Value/ Nilai non kegunaan } \\ \mathrm{EV}= & \text { Manfaat keberadaan (Existence } \\ & \text { value) }\end{aligned}$

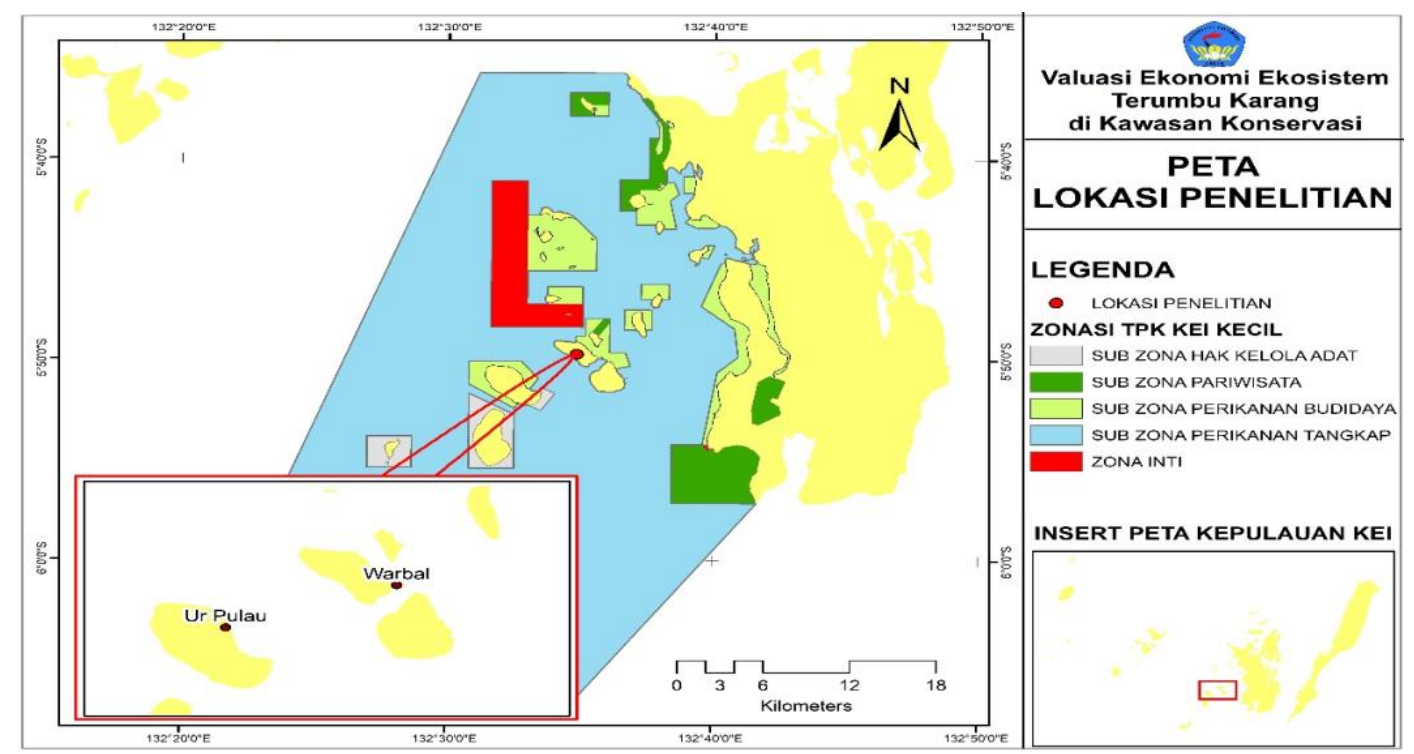

Gambar 1. Peta lokasi penelitian 
Berbasis formula TEV tersebut maka nilai manfaat langsung (direct uses value) terumbu karang Pulau Warbal dihitung menggunakan metode analisis perubahan produktivitas dan pendekatan harga pasar dengan formula (Barton, 1994; Wahyudin 2004) sebagai berikut:

$$
\text { DUV = ML1 + ML2 + ML3 }
$$

Keterangan:

ML1 = Nilai Manfaat Perikanan Tangkap

ML2 = Nilai Manfaat Perikanan Budidaya

ML3 = Nilai Manfaat Pariwisata

Nilai manfaat tidak langsung pembangunan pemecah gelombang dihitung berbasis biaya pengganti per $\mathrm{m}^{3}$ dikalikan dengan panjang pantai yang dilindungi terumbu karang, dengan formula (Setiyowati, dkk., 2016) sebagai berikut:

\section{$\operatorname{MTL} \mathrm{A}_{1}=\operatorname{LTK} x\left(\sum_{i=1}^{n} J S B i x \mathrm{HBi}\right)$}

Keterangan:

$\mathrm{MTL}_{1} \mathrm{~A}=$ Manfaat Tidak Langsung pemecah ombak

LTK = Luas Tutupan Karang $\left(\mathrm{m}^{2}\right)$

JSBi = Jumlah satuan bahan yang digunakan (unit)

Hbi = Harga satuan bahan yang digunakan (Rp/unit)

Nilai serapan karbon oleh ekosistem terumbu karang mengacu pada Soemarwato (2001) bahwa nilai 1 ton karbon berkisar antara US\$1 - US\$28 dengan asumsi harga US\$10 per ton atau setara Rp.140.800, nilai produktivitas primer terumbu karang $2500 \mathrm{gr} / \mathrm{m}^{2} /$ tahun. Nilai manfaat pilihan (option use) dari retumbu karang dihitung menggunakan pendekatan dari Fauzi\&Anna (2005), dengan formula sebagai berikut:

Keterangan:

$$
\mathrm{MP}=(\mathbf{N b} \times \mathbf{L})
$$

$\mathrm{MP}=$ Manfaat Pilihan

$\mathrm{Nb}=$ Nilai Keanekaragaman Hayati Terumbu Karang (Rp 493.696./ha)

$\mathrm{L}=$ Luas Kawasan Terumbu Karang (ha)

Menghitung nilai manfaat keberadaan dengan menggunakan teknik pendekatan kesediaan membayar (willingness to pay) dapat diperoleh dari hasil perhitungan nilai tengah mengikuti dengan formula berdasarkan (FAO, 2000):

$$
\mathbf{M W T P}=\frac{1}{n} \sum_{i=1}^{n} y_{i}
$$

Keterangan:

$\mathrm{n} \quad=$ Besaran atau jumlah sampel

yi = Besaran WTP yang diberikan responden ke-i

Guna mengetahui hubungan antara WTP dengan karakteristik responden terhadap sumberdaya yang selama ini dimanfaatkannya, dihitung menggunakan formula berikut:

$$
W T P=\beta_{0}+\sum_{i=1}^{n} \beta_{i} X_{i}
$$

Keterangan:

WTP $=$ Kemampuan membayar responden terhadap suatu sumberdaya

$\mathrm{X} \mathrm{i}=$ Parameter pengukuran ke-i (seperti pendapatan, umur, pendidikan)

$\mathrm{n} \quad=$ Jumlah besaran sampel

$\mathrm{i}=$ Jumlah Variabel

ßo $=$ Nilai konstanta dari model

$\beta \mathrm{I}=$ Koefisien regresi masing-masing variable ke-i

Total pendapatan dari kesediaan membayar masyarakat dihitung dengan formula berikut:

$$
\text { TB }=\text { WTP } x \text { Pti }
$$

Keterangan:

$\mathrm{TB}=$ Total Benefit

Pti = Jumlah populasi pada tahun ke $\mathrm{i}$

Strategi pengelolaan ekosistem terumbu karang Pulau Warbal dan perairan sekitarnya dirumuskan melalui dua tahapan. Tahap pertama, mengidentifikasi faktor lingkungan SWOT, yaitu faktor lingkungan internal dan eksternal (Rangkuti, 2006). Tahap kedua, data SWOT dipakai untuk mengembangkan 4 tipe pilihan strategi melalui analisis TOWS, yaitu persilangan faktor lingkungan strategis $\mathrm{SO}, \mathrm{ST}$, WO dan WT (Rangkuti, 2006).

\section{HASIL DAN PEMBAHASAN}

\section{Analisis Ekonomi Nilai Pemanfataan Langsung}

Enam spesies ikan yang menjadi target penangkapan nelayan-nelayan Desa Warbal, dan data jumlah hasil tangkapan/tahun setiap jenis ikan dapat dilihat pada Tabel 1. Selain 
perikanan tangkap, sejak tahun 2009 masyarakat Desa Warbal mulai mengembangkan budidaya jenis rumput laut Eucheuma cottonii penghasil karaginan yang banyak diperlukan untuk industri farmasi maupun pangan (Sugandi\&Putra, 2017; Ongge\&Rumaikewi, 2020). Namun, perubahan produksi budidaya jenis rumput laut ini dari tahun ke tahun mengalami fluktuasi, dan dipengaruhi dua hal yaitu adanya hama penyakit yang menyerang dan harga jual yang turun drastis tahun 2017-2018. Tahun 2018 produksi total rumput laut Desa Warbal mencapai 12 ton rumput laut kering, dengan jumlah pembudidaya 30-40 orang.

Nilai manfaat langsung perikanan tangkap dan perikanan budidaya di Desa Warbal dalam satu tahun tersaji dalam Tabel 2. Terdapat catatan penting bahwa tidak semua responden pembudidaya memakai armada kapal/perahu untuk menuju ke lokasi budidaya miliknya. Beberapa pembudidaya hanya perlu berjalan kaki menuju lokasi budidaya, sehingga biaya operasional untuk usaha budidaya sedikit lebih rendah.

\section{Valuasi Pariwisata Yang Berasosiasi Dengan Terumbu Karang}

Nilai ekonomi pemanfaatan yang berasal dari aktivitas wisata pantai dihitung berbasis jumlah pengeluaran rata-rata dari sejumlah wisatawan yang berkunjung per tahun. Dalam menghitung jumlah biaya yang dikeluarkan wisatawan saat berwisata di pantai Ngurtavur sebesar Rp 200.000/boat, akomodasi berupa jasa speed boat dari pelabuhan DebutNgurtavur (Warbal) sebesar Rp 700.000/boat.
Data tahun 2018 yang bersumber dari pengelola karcis masuk diperoleh pada pantai Ngurtavur terdapat kunjungan 597 speed boat dengan jumlah penumpang per/speed boat 6-9 orang.

Total nilai pemanfaatan langsung dari pariwisata yang berasosiasi dengan terumbu karang sebesar $\mathrm{Rp}$ 567.150.000. Aktivitas wisata merupakan jasa yang memiliki dampak ikutan atau multiplier effect. Selain biaya transportasi speed boat, terdapat juga biaya lain-lain berupa konsumsi makanan yang dikeluarkan setiap wisatawan yang dirasakan masyarakat di luar Desa Warbal berupa konsumsi makanan dan cendramata yang tidak tersedia di kawasan pantai Ngurtavur. Manfaat ekonomi dari kegiatan wisata bagi masyarakat Desa Warbal, yaitu skema pengelolaan dengan sistem bagi hasil 30:30:40, berturut-turut 30\% untuk dana pendidikan anak penduduk, $30 \%$ untuk keagamaan dan $40 \%$ untuk operasional objek wisata.

\section{Analisis Nilai Ekonomi Pemanfaatan Tidak Langsung Terumbu Karang}

Manfaat ekologis terumbu karang selain sebagai tempat hidup ikan dan biota yang berasosiasi dengannya, juga manfaat ekologi sebagai perlindungan pantai dan penyerapan karbon (Maharmingnastiti, dkk., 2015; Azhar, 2016) Dalam penelitian ini, manfaat tersebut diklasifikasikan sebagai manfaat tidak langsung (indirect use value). Jika tidak ada karang batu yang menghasilkan sedimen kapur, fungsi terumbu karang sebagai pemecah ombak akan berkurang sehingga akan terjadi abrasi pantai.

Tabel 1. Jumlah hasil tangkapan responden nelayan Desa Warbal

\begin{tabular}{lc}
\hline \multicolumn{1}{c}{ Jenis (Spesies) } & Hasil Tangkapan (Kg/Thn) \\
\hline Ikan baronang (Siganus lineatus) & 1.410 \\
Ikan Ekor kuning (Caesio cuning) & 3.401 \\
Ikan lencam (Lethrinus nebulosus) & 1.257 \\
Ikan kembung (Rastrelliger kanagurta) & 8.397 \\
Ikan layang biru (Decapterus macarellus) & 10.148 \\
Ikan kerapu putih (Plectropomus maculatus) & 825 \\
\hline
\end{tabular}


DOI: https://doi.org/10.30598/TRITONvol17issue2page104-116

Tabel 2. Nilai manfaat langsung dari aktivitas perikanan di Desa Warbal

\begin{tabular}{cccc}
\hline $\begin{array}{c}\text { Manfaat } \\
\text { Perikanan }\end{array}$ & Nilai Produksi (Rp/Thn) & Biaya Produksi (Rp/Thn) & Total Keuntungan (Rp/Thn) \\
\hline Tangkap & 636.948 .333 & 165.648 .050 & 471.300 .283 \\
Budidaya & 172.200 .000 & 118.345 .000 & 53.855 .000 \\
\hline Sumber: Data hasil wawancara yang diolah, 2019 & &
\end{tabular}

Sumber: Data hasil wawancara yang diolah, 2019

Luas daerah yang terlindung terumbu karang pada perairan Pulau Warbal dan sekitarnya sebesar $975 \mathrm{~km}^{2}$ dan harga satuan rata-rata pembuatan tanggul standar pemecah ombak, maka rata-rata biaya yang diperlukan per $\mathrm{m}^{3}$ sebesar $\mathrm{Rp}$ 550.000. Satuan ini mengacu pada standar biaya penelitian sebelumnya (Mira $d k k, 2017$ ) di perairan Kepulauan Banda, dengan estimasi tiap $1 \mathrm{~m}$ panjang pemecah gelombang memiliki dimensi sebesar $6 \mathrm{~m}^{3}$, dengan asumsi lebar $1 \mathrm{~m}$ dan ketinggian $6 \mathrm{~m}$. Jumlah unit yang diperlukan $\mathrm{Rp}$ 58.080.000.000. Jumlah ini merupakan nilai yang diperlukan untuk jangka waktu 10 tahun masa pakai. Oleh karena itu, nilai manfaat tidak langsung terumbu karang di Pulau Warbal sebagai pengganti tanggul pemecah gelombang sebesar Rp 5.808.000.000/tahun atau sekitar Rp 5.956.923/ha/tahun, sekaligus merupakan nilai manfaat terumbu karang sebagai penahan ombak per tahun dengan pendekatan replacement cost method.

Nilai serapan karbon ekosistem terumbu karang (Soemarwato, 2001) menunjukan nilai 1 ton karbon berkisar antara US\$1-US\$28 dengan asumsi harga US $\$ 10$ per ton atau setara dengan Rp. 140.800 nilai produktivitas primer terumbu karang sebesar $2500 \mathrm{gr} / \mathrm{m}^{2} /$ tahun. Dengan demikian, nilai serapan karbon diperoleh dengan mengalikan luasan terumbu karang dengan nilai serapan karbon yang ada:

- 9,75 ha $\times 10.000 \mathrm{~m}^{2}$ x $2500 \mathrm{gr} / \mathrm{m}^{2} / \mathrm{thn} \times$ $1 / 1.000 .000$ ton/gr $=2.437,5$ ton/tahun

- Nilai karbon US\$ 10 per ton (nilai tukar, US\$ 1= Rp 14.080,- saat penelitian)

- Berbasis perhitungan itu, maka nilai serapan karbon oleh terumbu karang di perairan Pulau Warbal dan sekitarnya adalah $2.437,5$ × 10 × Rp 14.080,- = Rp 343.200.000,-/tahun.

Total nilai serapan karbon oleh ekosistem terumbu karang Pulau Warbal dan perairan sekitarnya lebih kecil dari ekosistem terumbu karang di Taman Wisata Perairan (TWP) Kapoposang yaitu Rp. 2.734.518.000.-, dengan luas terumbu karang 1.156 ha (Haslindah, 2012). Kenyaataan ini wajar karena luas terumbu karang di kawasan Pulau Warbal dan perairan sekitarnya jauh lebih kecil dibanding TWP Kapoposang.

\section{Nilai Manfaat Pilihan (Option Price)}

Pendekatan yang dilakukan untuk menghitung manfaat pilihan dalam penelitian ini menggunakan nilai pemeliharaan sumberdaya yang potensial di masa yang akan menggunakan biodiversity value (nilai keanekaragaman hayati) ekosistem terumbu karang. Keanekaragaman hayati ikan karang yang ada di Indonesia diperkirakan sebanyak 592 spesies (Dahuri, 2003).

Terumbu karang yang hidup di daerah tropis cenderung memiliki diversitas tinggi, tetapi tingginya keanekaragaman jenis karang di daerah tropis umumnya berada dalam kondisi yang tidak seimbang. Jika tidak terjadi gangguan, keanekaragamannya akan turun (disturbance) dalam skala menengah, baik frekuensi maupun intensitasnya. Sebaliknya keanekaragaman terendah terjadi pada kondisi ekstrim, yaitu tidak ada gangguan atau gangguan sangat besar (Supriharyono, 2007). Menurut Allen (2002), di Kepulauan Raja Ampat terdapat kenaekaragaman spesies ikan karang tertinggi di dunia dan sedikitnya terdapat 970 spesies karang.

\section{Nilai Non Pemanfaatan \\ Nilai Manfaat Keberadaan (Exiscetence Value )}

Nilai WTP responden terhadap keberadaan ekosistem terumbu karang Pulau Warbal dan perairan di sekitarnya disajikan pada Tabel 3. Hasil uji analisis regresi linear berganda digunakan untuk mengukur intensitas hubungan antara dua variable atau lebih. WTP 
merupakan variable terikat (dependent variable) sedangkan umur, pendapatan dan tingkat pendidikan merupakan variabel bebas (independent variable).

Berdasarkan hasil persamaan regresi (Tabel 4) diperoleh koefisien umur responden sebesar 228,1 yang artinya jika ada perubahan umur responden sebesar $1 \%$ maka akan ada peningkatan WTP sebesar 228\%. Koefisien variabel tingkatan Pendidikan sebesar 11860,3 maka dapat diestimasi bahwa jika ada peningkatan level pendidikan responden sebesar $1 \%$ akan ada peningkatan WTP sebesar $11.8 \%$. Koefisien variabel pendapatan sebesar 4536,9, artinya jika ada peningkatan pendapatan $1 \%$ maka akan ada peningkatan WTP sebesar $4.5 \%$. Koefisien determinasi (R) diperoleh sebesar $20 \%$, artinya variabel bebas hanya dapat menjelaskan variabel terikat sebesar $20 \%$ atau $80 \%$ dijelaskan oleh variabel lain yang tidak dimasukan dalam model yang mempengaruhi nilai WTP. Total benefit atau penerimaan yang diperkirakan dapat diperoleh oleh pengelola adalah rata rata WTP sebesar Rp.31.500 dikalikan jumlah populasi di Desa Warbal seebsar 579 jiwa, maka nilai total WTP tersebut yaitu sebesar Rp 18.238.500.

\section{Nilai Ekologi, Ekonomi dan Sosial Ekosistem Terumbu Karang}

Nilai manfaat ekonomi adalah nilai yang langsung dirasakan masyarakat dalam aktivitas perekonomiannya melalui usaha jasa pariwisata, perikanan tangkap dan budidaya rumput laut. Nilai manfaat ekologi ekosistem terumbu karang kawasan Pulau Warbal dan perairan di sekitarnya adalah tinggi dibanding nilai ekonomi, terutama nilai sosial terumbu karang tersebut (Tabel 5). Secara rinci nilai ekologi, terutama sebagai penahan ombak (gelombang) mencapai $79,82 \%$ dan hal ini sama dengan nilai ekologi terumbu karang di kabupaten Wakatobi (Ramadhan, dkk., 2016), khususnya sebagai pelindung lingkungan pesisir yang mencapai lebih dari $79 \%$. Dampak positif dari aktivitas ekonomi di terumbu karang Pulau Warbal dan perairan di sekitarnya yaitu hampir seluruh masyarakat dapat menyekolahkan anaknya hingga perguruan tinggi, kebutuhan keluarga terpenuhi, dan masyarakat dapat membangun rumah. Dalam hal ini, tingkat kesejahteraan masyarakat meningkat melalui peningkatan pengelolaan sumberdaya laut yang baik.

Tabel 3. Data Responden WTP menurut jenis pekerjaan dan pendapatan

\begin{tabular}{lcccc}
\hline \multicolumn{1}{c}{ Pekerjaan } & WTP $(\mathrm{Rp} / \mathrm{Thn})$ & $\begin{array}{c}\text { Pendapatan } \\
(\mathrm{Rp} / \mathrm{Thn})\end{array}$ & $\begin{array}{c}\text { Mean } \\
(\mathrm{Rp} / \mathrm{Thn})\end{array}$ & $\%$ \\
\hline Nelayan & $20.000-50.000$ & 7.055 .556 & 30.625 & 0,004 \\
Petani & $25.000-100.000$ & 8.833 .333 & 50.000 & 0,005 \\
Ibu Rumah Tangga & $10.000-50.000$ & 5.500 .000 & 26.667 & 0,004 \\
Pembudidaya & $20.000-50.000$ & 8.800 .000 & 27.000 & 0,003 \\
Pelajar & $<20.000$ & 5.000 .000 & 20.000 & 0,004 \\
\hline
\end{tabular}

Sumber: Data hasil wawancara yang diolah, 2019

Tabel 4. Hasil analisis reegresi liniear berganda WTP

\begin{tabular}{lrrrr}
\hline \multicolumn{4}{c}{ Regression Statistics } & \\
\hline Multiple R & & & & 0,57 \\
R Square & & & & 0,33 \\
Adjusted R Square & & & & 0,20 \\
\hline & Coefficients & Standard Error & t Stat & P-value \\
\hline & $-34978,0$ & 30231,7 & $-1,2$ & 0,3 \\
Intercept & 228,1 & 396,5 & 0,6 & 0,6 \\
Umur & 11860,3 & 6598,4 & 1,8 & 0,1 \\
Tingkat Pendidikan & 4536,9 & 1829,9 & 2,5 & 0,0 \\
Pendapatan & & & & \\
\hline
\end{tabular}


DOI: https://doi.org/10.30598/TRITONvol17issue2page104-116

Tabel 5. Nilai manfaat ekologi, ekonomi dan sosial terumbu karang Pulau Warbal dan perairan di sekitarnya

\begin{tabular}{l|r|r}
\hline \multicolumn{1}{c|}{ Jenis Nilai } & Nilai (Rp/Tahun) & Proporsi (\%) \\
\hline Nilai Ekologi & 6.156 .013 .536 & 84,61 \\
- Terumbu Karang & 5.808 .000 .000 & \\
a. Penahan Ombak & 4.813 .536 & \\
b. Keanekaragaman hayati & 343.200 .000 & \\
c. Nilai Serapan Karbon & 1.101 .305 .243 & 15,14 \\
\hline Nilai Ekonomi & & \\
- Terumbu Karang & 471.300 .283 & \\
a. Penangkapan Ikan & 53.855 .000 & \\
b. Budidaya & 567.150 .000 & 0,25 \\
c. Pariwisata & 18.250 .000 & \\
\hline Nilai Sosial & & \\
- Terumbu Karang & 18.250 .000 & 100 \\
a. Nilai manfaat keberadaan $(W T P)$ & $\mathbf{7 . 2 7 5 . 6 0 3 . 8 1 9}$ & \\
\hline \multicolumn{2}{c}{ T O T A L } &
\end{tabular}

Sumber: Data primer yang diolah, 2019

\section{Nilai Ekonomi Total Terumbu Tarang Pulau Warbal Dan Perairan Sekitarnya}

Nilai Ekonomi Total (TEV) terumbu karang Pulau Warbal dan perairan di sekitarnya (total nilai pemanfataan dan non pemanfaatan) sebesar Rp. 7.275.603.819/tahun (Tabel 6) atau setara dengan Rp 746.215.776/ha/tahun. Nilai ekonomi total terumbu karang Pulau Warbal dan perairan di sekitarnya lebih kecil dari total nilai ekonomi yang dihasilkan dari barang dan jasa ekosistem terumbu karang di Wakatobi yaitu lebih dari 4 triliun rupiah, tetapi jika diestimasi per hektar terumbu karang per tahun lebih besar dari total nilai ekonomi yang dihasilkan dari barang dan jasa ekosistem terumbu karang di Wakatobi tersebut, yaitu Rp.163.000.000/ha/tahun (Ramadhan $d k k$, 2016). Perbedaan ini disebabkan oleh luas terumbu karang Wakatobi jauh lebih luas dibanding terumbu karang Pulau Warbal dan perairan di sekitarnya yang hanya sekitar 9,7 ha.

Perubahan produktifitas (change in productivity) secara konseptual merupakan pendekatan yang dilakukan akibat adanya gangguan terhadap sumberdaya, sehingga terjadi perubahan aliran dari barang dan jasa terganggu (Adriyanto, 2004). Ekosistem terumbu karang memiliki fungsi sebagai daerah pemijahan (spawning ground), pembesaran (nursery ground), dan daerah mencari makan (feeding ground) serta memberikan stok unsur hara untuk perairan disekitarnya. Oleh karena itu, luas kawasan pesisir menjadi input bagi produktifitas hasil tangkapan ikan yang menjadi produk akhir bagi masyarakat.

Berdasarkan hasil penelitian diperoleh luas terumbu karang Pulau Warbal dan perairan sekitarnya sebesar 9,7 ha dengan perhitungan nilai ekonomi total untuk jangka panjang yaitu 50 tahun. Hal ini dikarenakan 50 tahun merupakan waktu yang diperlukan terumbu karang untuk tumbuh akibat adanya kerusakan agar dapat mengembalikan 50\% dari kondisi semula dan berproduksi lagi (Burke, $d k k$, 2002). Mengacu pada Discount rate yang dikeluarkan Bank Indonesia di awal tahun Januari-September 2019 sebesar 6\%, maka hasil analisis perubahan produktifitas (Tabel 7) menunjukkan jika terjadi kerusakan atau hilangnya luasan satu (1) ha terumbu karang di Desa Warbal maka akan hilang sekitar $\mathrm{Rp}$ 205.048.787/ha/tahun. Sumberdaya terumbu karang sebagai natural capital (Putri, 2009) akan memberi kontribusi terhadap perekonomian dan kesejahteraan masyarakat, terutama masyarakat di sekitar ekosistem terumbu karang (Widayatun, 2011). 
Tabel 6. Nilai Ekonomi Total terumbu karang Pulau Warbal dan perairan di sekitarnya

\begin{tabular}{|c|c|c|c|}
\hline No & Jenis Manfaat & $\begin{array}{c}\text { Total } \\
\text { (Rp/Thn) }\end{array}$ & $\begin{array}{c}\text { Persentase } \\
(\%)\end{array}$ \\
\hline \multicolumn{4}{|c|}{ Nilai Pemanfaatan (Use Value) } \\
\hline 1. & $\begin{array}{l}\text { Manfaat Langsung (Direct use Value) } \\
-\quad \text { Perikanan Tangkap } \\
-\quad \text { Budidaya Rumput Laut } \\
-\quad \text { Pariwisata } \\
\end{array}$ & $\begin{array}{r}471.300 .283 \\
53.855 .000 \\
567.150 .000 \\
\end{array}$ & $\begin{array}{l}6,48 \\
0,74 \\
7,92\end{array}$ \\
\hline 2 & $\begin{array}{l}\text { Manfaat Tidak Langsung (Indirect use value) } \\
\text { - } \quad \text { Pelindung Pantai } \\
\text { - } \quad \text { Serapan Karbon }\end{array}$ & $\begin{array}{r}5.808 .000 .000 \\
343.200 .000 \\
\end{array}$ & $\begin{array}{r}79,83 \\
4,72 \\
\end{array}$ \\
\hline 3 & Manfaat Pilihan (Option Value) & 4.813 .536 & 0,07 \\
\hline \multicolumn{4}{|c|}{ Nilai Non Pemanfaatan (Non Use Value) } \\
\hline 4 & Manfaat Keberadaan (Existence Value) & 18.250 .000 & 0,25 \\
\hline \multicolumn{2}{|c|}{ Nilai Ekonomi Total (total economy value) } & 7.275.603.819 & 100 \\
\hline
\end{tabular}

Tabel 7. Nilai Perubahan Produktivitas Terumbu Karang di Ohoi Warbal

\begin{tabular}{cl}
\hline Formula Pendekatan & Change in Productivity \\
\hline Present value generated per hectare & Rp. 205.048.787/ha \\
Residual rent approach & Rp. 185.523.931/ha \\
\hline Sumber: Data primer yang diolah, 2019 &
\end{tabular}

\section{Implikasi Kebijakan Pengelolaan Ekosistem Terumbu Karang Kawasan Pulau Warbal}

Berdasarkan hasil penelitian
teridentifikasi delapan faktor Kekuatan (S) dan lima faktor Kelemahan (W) untuk lingkungan internal. Selain itu, untuk lingkungan eksternal maka teridentifikasi lima faktor Peluang $(\mathrm{O})$ dan empat faktor Ancaman (T) (Tabel 8). Persilangan faktor lingkungan internal yaitu Kekuatan (S) dan Kelemahan (W) dengan faktor lingkungan eksternal meliputi Peluang $(\mathrm{O})$ dan Ancaman ( $\mathrm{T}$ ) melalui analisis TOWS menghasilkan 11 strategi dan 22 arahan kebijakan pengelolaan ekosistem terumbu karang beserta sumberdaya perikanan yang dimiliki dan pemanfatan di kawasan Pulau Warbal dan sekitarnya. Strategi dan arahan pengelolaan itu terdistribusi pada empat kelompok strategi yaitu strategi SO sebanyak tiga strategi dengan enam arahan, strategi ST sebanyak empat strategi dengan delapan arahan, strategi WO sebanyak dua strategi dengan empat arahan, serta strategi WT sebanyak dua strategi dengan empat arahan kebijakan pengelolaan ekosaistem terumbu karang, termasuk sumberdaya perikanan yang dimiliki dan pemanfaatannya di kawasan Pulau Warbal dan perairan sekitarnya.

\section{Strategi S - O (Strengths - Opportunities)}

Strategi 1. Menyusun roadmap dan grand design pengembangan pariwisata berorientasi ekowisata, yang dapat diwujudkan melalui arahan pengelolaan, yaitu: a) dinas terkait bersama dengan pemerintah desa membentuk tim dalam menyusun grand design yang didalamnya memuat masterplan pengembangan kawasan ekowisata dan RIPPOW yang mengacu pada RIPPDA Kabupaten Maluku Tenggara dan RIPPDA Provinsi Maluku; b) melakukan kajian bersama dengan stakeholder terkait yaitu akademisi dan NGO untuk identifikasi potensi kawasan wisata yang didalamnya juga mengatur daya dukung pemanfaatan (carrying capacity).

Strategi 2. Mengoptimalkan pendampingan oleh NGO untuk pemberdayaan masyarakat lokal. Strategi ini dapat diwujudkan melalui arahan pengelolaan sebagai berikut: a) NGO bersama Dinas/Badan terkait dan masyarakat menyusun rencana peningkatan kualitas kepariwisataan, budidaya perikanan (laut) dan penagkapan ikan berwawasan lingkungan; b) NGO melakukan pendampingan masyarakat Desa Warbal melalui pelatihan untuk mengembangkan kapasitas sumberdaya manusia dalam aktivitas budidaya, penangkapan, aktivitas pariwisata. 
Tabel 8. Matriks lingkungan SWOT dan analisis TOWS pengelolaan sumberdaya terumbu karang kawasan Pulau Warbal dan perairan sekitarnya

\begin{tabular}{|c|c|c|}
\hline & & \\
\hline EFAS & $\begin{array}{l}\text { Strength (S) } \\
\text { 1. Termasuk dalam KKP3K jenis } \\
\text { TPK Kei Kecil Barat (zona } \\
\text { pemanfaatan) } \\
\text { 2. Memiliki } 9.7 \text { ha Terumbu K } \\
\text { 3. Kekayaan spesies, Sediaan } \\
\text { Cadang dan Potensi ikan di } \\
\text { terumbu karang kawasan Pulau } \\
\text { Warbal yang tinggi } \\
\text { 4. Menjadi Desa sentral produksi } \\
\text { rumput laut } \\
\text { 5. Memiliki daya tarik wisata } \\
\text { pantai pasir timbul } \\
\text { 6. Ada dukungan pengelolaan } \\
\text { wisata oleh masyarakat lokal. } \\
\text { 7. Memiliki potensi sumberdaya } \\
\text { perikanan } \\
\text { 8. Memiliki kebijakan pengelolaan } \\
\text { hasil usaha jasa wisata }\end{array}$ & $\begin{array}{l}\text { Weakness (W) } \\
\text { 1. Terumbu karang rusak karena } \\
\text { penambangan karang oleh } \\
\text { masyarakat untuk bahan bangunan } \\
\text { dan masih terjadi aktivitas } \\
\text { pengeboman } \\
\text { 2. Belum ada rencana kelola zona } \\
\text { pemanfaatan pada Pulau Warbal dan } \\
\text { perairan di sekitarnya } \\
\text { 3. Sarana prasarana penunjang } \\
\text { pariwisata belum memadai. } \\
\text { 4. Belum ada kelompok masyarakat } \\
\text { khusus pengelola wisata bahari. } \\
\text { 5. Belum ada kelompok masyarakat } \\
\text { pengawas perikanan }\end{array}$ \\
\hline Oppurtunity $(\mathbf{O})$ & & \\
\hline $\begin{array}{l}\text { 1. Permen KP No57/ Permen- } \\
\text { KP/2014 } \\
\text { 2. Permenpar No 14/2016 } \\
\text { 3. Ada Dinas Perikanan Dinas } \\
\text { Pariwisata Kab. Maluku } \\
\text { Tenggara } \\
\text { 4. Menjadi Desa binaan WWF } \\
\text { Indonesia } \\
\text { 5. Promosi pariwisata yang } \\
\text { dilakukan trip operator secara } \\
\text { massif }\end{array}$ & 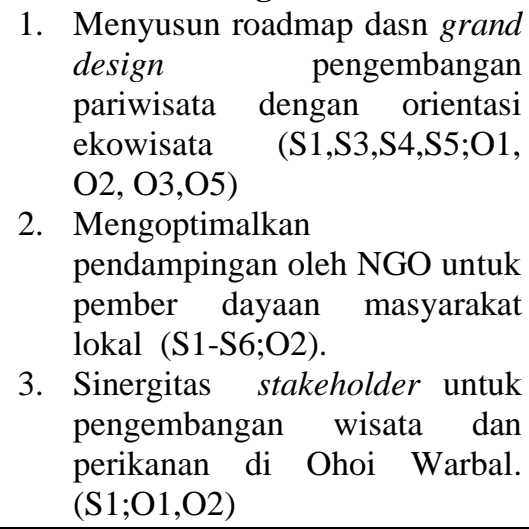 & $\begin{array}{l}\text { 1. Membentuk kelompok } \\
\text { POKMASWAS dan POKDARWIS } \\
\text { di bawah pendam pingan Dinas } \\
\text { Perikanan, Dinas Pariwisata dan } \\
\text { NGO (W1-5;O1,O2,O4) } \\
\text { 2. Alokasi ABPD/APBN Dinas } \\
\text { Terkait menyu sun rencana pengelo } \\
\text { laan zona pemanfaat an di Pulau } \\
\text { Warbal dan pemenuhan kebutuhan } \\
\text { sarpras objek wisata (W1- } \\
\text { W5;O1,O4) }\end{array}$ \\
\hline $\begin{array}{l}\text { Threatness (T) } \\
\text { 1. Aktivitas pengeboman ikan } \\
\text { masih terjadi. } \\
\text { 2. Persaingan objek wisata pantai } \\
\text { lain. } \\
\text { 3. Aktivitas wisata yang tidak } \\
\text { ramah lingkungan } \\
\text { 4. Rantai pasar hasil panen } \\
\text { budidaya rumput laut tidak } \\
\text { berjalan dengan baik }\end{array}$ & $\begin{array}{l}\text { Strategi S-T } \\
\text { 1. Meningkatkan patroli ber sama } \\
\text { antar Instansi pengelola KKP3K } \\
\text { dan masy. (S1;T1) } \\
\text { 2. Menata kawasan wisata dengan } \\
\text { branding ekowisata } \\
\text { (S1,S3;T2,T3) } \\
\text { 3. Menerpkan prinsip best } \\
\text { management practices dalam } \\
\text { kawasan wisata(S1,S3;T2,T3) } \\
\text { 4. Membentuk kelompok usaha } \\
\text { bersama (KUB) budidaya } \\
\text { rumput laut (S2;T4) }\end{array}$ & $\begin{array}{l}\text { Strategi W-T } \\
\text { 1. Memperbaiki terjumbu dan } \\
\text { mengadvokasi diter bitkannya } \\
\text { regulasi yang mengatur pengelolaan } \\
\text { kawasan pesisir skala desa (W1- } \\
\text { W5;T1-T3) } \\
\text { 2. Mendorong Instansi terkait } \\
\text { membentuk Lembaga pengelola } \\
\text { KKP3K TPK Kei Kecil (W1- } \\
\text { W5;T1-T3) }\end{array}$ \\
\hline
\end{tabular}

Strategi 3. Sinergitas antara stakeholder guna pengembangan wisata dan perikanan di Ohoi Warbal. Strategi ini dapat diwujudkan melalui arahan pengelolaan sebagai berikut: a) Pemerintah, NGO dan Private Sector bekerjasama menyusun dan mengimplementasikan program dan kegiatan terkait intervensi dari masing-masing lembaga dan instansi untuk mengembangkan wisata di kawadan Pulau Warbal dan perairan di sekitarnya; b) Menyusun dan mengimplementasikan program serta kegiatan pemanfaatan dan pengelolaan sumberdaya ikan di terumbu karang dan perairan sekitarnya, serta budidaya rumput laut yang ada di Pulau Warbal dan perairan disekitarnya. 


\section{Strategi W - O (Weakness - Opportunities)}

Strategi 1. Membentuk kelompok POKMASWAS dan POKDARWIS dibawah pendampingan Dinas Perikanan, Dinas Pariwisata dan NGO. Strategi ini dapat diwujudkan melalui arahan pengelolaan sebagai berikut: a) Menginisisasi pembentukan kelompok masyarakat pengawas (POKMASWAS) dan kelompok sadar wisata (POKDARWIS); b) Menyiapkan sumberdaya manusia dalam kedua kelompok ini merupakan penduduk yang dalam aktivitas keseharian dan mata pencaharian bersinggungan langsung dengan aktivitas melaut dan pariwisata.

Strategi 2. Pengalokasian ABPD/APBN Dinas terkait untuk menyusun rencana pengelolaan zona pemanfaatan pada Pulau Warbal dan perairan sekitarnya, serta pemenuhan kebutuhan sarana dan prasarana objek wisata. Strategi ini dapat dilaksanakan melalui arahan pengelolaan sebagai berikut: a) Dinas Perikanan dan institusi terkait melalui Renstranya menyusun program dan implementasi pengelolaan zona pemanfaatan pada kawasan Pulau Warbal dan perairan sekitarnya; b) Dinas Pariwisata menganggarkan melalui dokumen Renstra dengan menetapkan lokus pengembangan destinasi prioritas wisata Pantai Ngurtavur.

\section{Strategi S - T (Strengths - Threats)}

Strategi 1. Meningkatkan intensitas patroli bersama antar Instansi pengelola Kawasan Konservasi dan masyarakat, dengan arahan pengelolaan sebagai berikut: a) Kerjasama PSDKP, Kantor Cabang Dinas Perikanan dan Kelautan Provinsi Maluku dan LSM dalam melakukan patroli secara rutin di wilayah perairan Pulau Warbal dan sekitarnya; b) Pelanggaran yang dilakukan oleh masyarakat dan ditemukan oleh satuan tugas patroli agar langsung dilakukan penindakan terhadap pelaku melalui proses hukum yang berlaku.

Strategi 2. Menata kawasan wisata dengan branding ekowisata. Strategi ini dapat diwujudkan melalui arahan pengelolaan berikut: a) menyusun dokumen masterplan dengan memperhatikan prinsip responsible marine tourism; b) menata kelola kawasan wisata sesuai permenpar No 14 tahun 2016 tentang Pedoman Destinasi Pariwisata Berkalanjutan.
Strategi 3. Menerapkan prinsip best management practices dalam kawasan wisata, dengan arahan pengelolaan, yaitu: a) Menyusun pedoman berwisata dan berinteraksi dengan satwa yang ada didalam kawasan wisata Pulau Warbal dan perairan disekitarnya.

Strategi 4. Membentuk kelompok usaha bersama (KUB) budidaya rumput laut disertai pendampingan dan penguatan kapasitas usahanya. Strategi ini dapat dilaksanakan melalui arahan berikut: a) Membentuk kelompok sebagai wadah untuk mengakomodir seluruh kepentingan pembudidaya rumput laut guna mengembangkan usahanya; b) Melakukan pendampingan melalui pelatihan teknik-teknik budidaya rumput laut dan penolahan pasca panaen yang sesuai; c) Dinas dan atau Badan terkait melakukan pengaturan dan menyediakan akses pasar bagi pembudidaya rumput laut.

\section{Strategi W - T (Weakness - Threats)}

Strategi 1. Memperbaiki terumbu karang yang rusak dan mengadvokasi penerbitan regulasi yang mengatur pengelolaan kawasan pesisir skala desa. Strategi ini dapat diimplementasikan melali arahan sebagai berikut: a) Dinas Perikanan Kabupaten Maluku Tenggara menyusun program dan melakukan rehabilitasi terumbu karang yang rusak akibat pemanfaatan yang tidak ramah lingkungan; b) Membentuk Tim pokja yang bertugas mengidentifikasi, menganalisis dan menyusun Peraturan Desa (Perdes) tentang pengelolaan sumberdaya di wilayah pesisir Pulau Warbal dan perairan di sekitarnya.

Strategi 2. Mendorong Instansi terkait untuk membentuk Lembaga pengelola KKP3K-TPK Kei Kecil. Strategi ini dapat dilakukan melalui arahan pengelolaan sebagai berikut: a) Pembentukan Lembaga Pengelola KKP3K-TPK Kei Kecil yang akan mendorong peningkatan efektivitas kawasan konservasi perairan termasuk Pulau Warbal dan perairan di sekitarnya; b) menyusun program dan kegiatan untuk menunjang perekonomian dari sisi perikanan, budidaya dan aktivitas wisata dengan tetap memperhatikan prinsip environmental sustainability. 


\section{KESIMPULAN}

Berdasarkan hasil dan pembahasan yang telah diuraikan, maka dirumuskan beberapa kesimpulan sebagai berikut:

- Nilai pemanfaatan sumberdaya terumbu karang sebesar Rp. 7.257.318.819/tahun. Nilai non pemanfaatan sumberdaya terumbu karang Pulau Warbal dan perairan di sekitarnya sebesar Rp. 18.250.000/tahun.

- Nilai ekonomi total dari pemanfaatan dan non pemanfaatan sumberdaya terumbu karang kawasan Pulau Warbal dan perairan sekitarnya mencapai Rp. 7.275.603.819/ tahun atau setara dengan Rp 746.215.776/ha/tahun.

- Dirumuskan 11 strategi dan 22 arahan pengelolaan ekosistem terumbu karang, termasuk sumberdaya perikanan dan pemanfaataannya di kawasan Pulau warbal dan sekitarnya, sehingga memberi manfaat ekonomi untuk kepentingan sosial masyarakat dengan tetap memperhatikan keberlanjutan ekologisnya.

\section{DAFTAR PUSTAKA}

Abrahamsz J., T. Alansar, T. Abdillah, M.M. Makailipessy, I.M. Thenu. 2017. Model Integrasi Efektivitas Pengelolaan Kawasan Konservasi dan Status Pengelolaan Perikanan: Kasus Taman Pulau Kecil Kei Kecil. Coastal and Ocean Journal 1(2): 179188.

DOI: https://doi.org/10.29244/COJ.1.2.179-188.

Allen, G.R. 2002. Reef Fishes of The Raja Ampat Islands, Papua Province, Indonesia. In A Marine Rapid Assessment of Raja Ampat Island, Papua Province, Indonesia. RAP Bulletin on Biological Assessment twentytwo.

Arisandi, A., B. Tamam, A. Fauzan. 2018. Profil Terumbu Karang Pulau Kangean, Kabupaten Sumenep, Indonesia. Jurnal Ilmiah Perikanan dan Kelautan 10(2): 76-83. http://doi.org/10.20473/ jipk.v10i2.10516.

Azhar, A. 2016. Pengaruh Perubahan Iklim Terhadap Terumbu Karang: Antara Dampak dan Perannya Dalam Siklus Karbon. Marine Journal 2(1): 1-13.

Barton, D.N. 1994 Economis Factors and Valuation of Tropical Coastal Resources. Universiteit I
Bergen. Senter for Miljo-Og Ressursstudier, Norway.

Burke, L., L. Selig, M. Spalding, 2002. Terumbu Karang Yang Terancam di Asia Tenggara: Ringkasan untuk Indonesia. World Resources Institute. 72 hal. ISBN 1-56973-510-7.

Dahuri R. 2003. Keanekaragaman Hayati Laut. Aset Pembangunan Berkelanjutan Indonesia. Penerbit PT Gramedia Pustaka Utama. Jakarta.

FAO, 2000. Application of Contingent Valuation Method in Developing Countries. FAO Economic and Social Development Papers No. 146/200. FAO, Rome.

Fauzi, A. \& S. Anna. 2005. Studi Valuasi Ekonomi Perencanaan Kawasan Konservasi Selat Lembeh, Sulawesi Utara. Jakarta: USAID, DKP dan Mitra Pesisir.

Haslinda. 2012 Valuasi Ekonomi Ekosistem Terumbu Karang Taman Wisata Perairan Kapoposang Kabupaten Pangkep. Tesis. Program Pascasarjana Universitas Hasanuddin, Makassar.

Putri, I. A. P. 2009. Valuasi Ekonomi Terumbu Karang Kawasan Konservasi Laut Kepulauan Seribu. Tesis. Sekolah Pascasarjana Institut Pertanian Bogor.

KKP. 2016. Keputusan Menteri Kelautan dan Perikanan RI Nomor 6/Kepmen-kp/2016, Tentang Kawasan Konservasi Pesisir dan Pulau-Pulau Kecil Pulau Kei Kecil, PulauPulau, dan Perairan Sekitarnya di Kabupaten Maluku Tenggara Provinsi Maluku.

Maharmingnastiti, W., A.W. Saputra, D. Wijayanto. 2015. Valuasi Ekonomi Ekosistem Terumbu Karang di Perairan Karang Kelop Kabupaten Kendal. Journal of Maquares 4(3): 188-194.

Mira M., S. Saptanto, Hikmah, 2017. Valuasi Ekonomi Terumbu Karang di Banda Neira. $J$. Sosek $\quad K P \quad 12(1)$ : $11-20$. .DOI:http://dx.doi.org/10.15578/jsekp.v12i1.6 284.

Ongge, D. \& N.E. Rumaikewi. 2020. Pengolahan Nori Rumput Laut (Eucheuma cottonii) Dengan Penambahan Daun Singkong (Manihot esculenta) di Kabupaten Biak Numfor. Jurnal Perikanan Kamasan 1(1): 2935 .

Ramadhan, A., Lindawati, N. Kurniasari, 2016. Nilai Ekonomi Terumbu Karang di Kabupaten Wakatobi. Jurnal Sosek KP 11 (2): 133-146.

Rangkuti, F. 2006. Analisis SWOT. Teknik Membedah Kasus Bisnis. PT. Gramedia Pustaka Utama. Jakarta. 
Rumkorem, O.L.Y., R. Kurnia, F. Yulianda. 2019. Asosiasi Antara Tutupan Komunitas Karang Dengan Komunitas Ikan Terumbu Karang di Pesisir Timur Pulau Biak, Kabupaten Biak Numfor. Jurnal Ilmu dan Teknologi Kelautan Tropis 11(3): 615-625.

Setiyowati, D., Supriharyono, I. Triarso. 2016. Valuasi Ekonomi Sumberdaya Mangrove di Kelurahan Mangunharjo, Kecamatan Tugu, Kota Semarang. Journal Saintek Perikanan 12 (1): 67-74. https://doi.org/10.14710/ ijfst.12.1.67-74.

Singarimbun M. \& S. Effendi. 2000 Metode Penelitian Survai. Lembaga Penelitian Penyelidikan, Pengembangan Ekonomi dan Sosial [LP3ES]. Jakarta.

Sugandi, W.K. \& G.M.D. Putra. 2017. Model Pengembangan Usaha Budidaya Rumput Lautu (Eucheuma cottonii) Dengan Pendekatan Causal Loop Diagram (Studi
Kasus di Pantai Cipatujah Kabupaten Tasikmalaya). Jurnal ilmiah Rekayasa dan Biosistem 5(1): 321-329.

Supriharyono. 2007. Konservasi Ekosistem Sumberdaya Hayati di Wilayah Pesisir dan Laut Tropis. PT. Gramedia Pustaka Utama. Jakarta.

Soemarwoto, O. 2001. Ekologi, Lingkungan Hidup dan Pembangunan. Djambatan Jakarta.

Wahyudin, Y. 2004. Karakteristik Sumberdaya Pesisir dan Laut Kawasan Teluk Pelabuhan Ratu Kabupaten Sukabumi. Disertasi. Program Studi Ekonomi Sumber daya Kelautan Tropika. Sekolah Pascasarjana. Institut Pertanian Bogor. Bogor.

Widayatun. 2011. Peran Masyarakat Dalam Pelestarian Terumbu Karang dan Dampaknya Terhadap Peningkatan Kesejahteraan. Jurnal Kependudukan Indonesia VI(2): 1-19. 